\title{
CRT-D Therapy in Heart Failure: How Much Do NYHA Class IV Patients Benefit?
}

\author{
MICHAEL H. LEHMANN, M.D. and KEITH D. AARONSON, M.D., M.S. \\ From the Department of Internal Medicine/Division of Cardiovascular Disease, University of Michigan School of Medicine, Ann Arbor, \\ Michigan, USA
}

\section{Editorial Comment}

Patients with advanced heart failure (HF) have high mortality rates, to a relatively greater extent in those with New York Heart Association (NYHA) functional class IV versus III, justifying consideration of cardiac transplantation in this high-risk population. ${ }^{1,2}$ For many of these patients, gains in pharmacologic therapy have helped significantly in delaying progression to transplantation requirement. However, even with the advent of angiotensin converting enzyme inhibitors, beta blockers, and aldosterone antagonists, overall attrition in the advanced HF population is still substantial.

Device therapy, first with implantable cardioverter defibrillators (ICDs) and, more recently, with cardiac resynchronization (CRT) or combination (CRT-D) devices, has provided documented survival benefit (or at least clinical benefit [the initial CRT trials]) beyond medical therapy alone in the advanced HF population. ${ }^{3-15}$ For clinical decision making and cost effectiveness considerations, it would be important to understand the extent to which NYHA functional class III and IV patients respond similarly or differentially to device therapy. Such understanding is hampered, however, by the relative paucity of information on outcomes with device therapy in the latter HF patient group.

\section{Limited Controlled Trial Data on Device Therapy in NYHA Class IV Patients}

The accompanying Table 1 lists 13 randomized clinical trials investigating outcomes of device therapy in patients (at least 100 enrollees per study), all of whom had baseline left ventricular (LV) systolic dysfunction (LV ejection fraction [LVEF] typically $\leq 0.35$ ); those in the various CRT/CRT$\mathrm{D}$ trials typically had additional objective evidence for $\mathrm{HF}$ besides reduced LVEF and high functional class. Patients in the 13 trials had mostly ischemic cardiomyopathy (72\% of ICD-only studies; and 54\% of CRT/CRT-D studies). Of note, NYHA functional class IV patients constituted only $4.2 \%$ of the total of 10,803 patients enrolled in these trials (1\% of ICD-only studies; and $10 \%$ of CRT/CRT-D studies). In contrast, NYHA class III patients constituted 9-30\% of ICD-only trials; and 72-100\% of CRT/CRT-D trials.

J Cardiovasc Electrophysiol, Vol. 17, pp. 491-494, May 2006.

Address for correspondence: Michael H. Lehmann, M.D., Women's Hosp L3119, Box 0273, University of Michigan Medical Center, 1500 East Medical Center Drive, Ann Arbor, MI 48109-0273. Fax: 734-763-7390; E-mail: lehmann@umich.edu

doi: 10.1111/j.1540-8167.2006.00478.x

\section{Paradoxical Finding of the Present Study Regarding NYHA Class IV vs. Class III Patients}

The report by Desai et al. in the present issue of the Jour$n a l^{16}$ offers some new data on responses of NYHA class IV versus class III populations to CRT-D therapy. Among 501 patients receiving CRT-D devices (as part of the Ventak $\mathrm{CHF} /$ Contak CD trial, for spontaneous or inducible sustained ventricular tachyarrhythmias and QRS duration $\geq 120 \mathrm{~ms}$ ), $45(9 \%)$ had NYHA class IV symptoms, 291 (58\%) class III, and the remainder class II. The authors analyzed predictors of appropriate ICD therapy delivery (either antitachycardia pacing or shock delivered for a rhythm classified as ventricular tachycardia [VT] or ventricular fibrillation [VF] by the treating electrophysiologist) at the relatively brief 6-month follow-up point. By multivariable analysis, the only independent predictors of appropriate ICD therapy were NYHA class and type of ICD indication (secondary vs. primary prevention): appropriate ICD therapy delivery was significantly greater in patients with NYHA class IV symptoms versus the other two classes, and in patients with a history of spontaneous ventricular tachyarrhythmias (secondary prevention group) versus those with inducible sustained VT (primary prevention, MADIT patient profile). Even after exclusion of NYHA class II patients, appropriate ICD therapy delivery at 6 months was $86 \%$ more likely to occur in NYHA class IV versus class III patients ( $\sim 37 \%$ vs. $\sim 19 \%$ incidences rates, respectively; $\mathrm{P}<0.04)$. This finding was independent of patient age, gender, LVEF, etiology of cardiomyopathy (ischemic vs. other) or type of HF medication used.

The authors' observations seem at variance with a body of data showing, proportionately, a much greater mortality from sudden cardiac death (SCD; presumably mediated principally by ventricular tachyarrhythmias) in NYHA class III versus class IV HF patients ( $\sim 60 \%$ vs. $\sim 20-33 \%$, respectively). ${ }^{1,2,17}$ Moreover, the crude SCD rate (actual number of SCDs per number of individuals at risk) in class IV patients is actually less than ${ }^{1}$ or equal to ${ }^{2}$ that of class III patients. Thus, the much greater incidence of appropriate ICD therapy delivery in class IV versus class III patients, as reported by Desai et al., ${ }^{16}$ appears paradoxical.

One might attempt to dismiss this seeming discrepancy by invoking non-equivalence between appropriate ICD therapy and aborted SCD events. While such a distinction is true in general, there are several problems with applying this argument in the case of an advanced HF population. For one thing, the notion that appropriate ICD shocks in these patients often represent brief episodes of non-sustained VT (or VF) is not that tenable in an era of non-committed ICDs that take a "second look" after capacitor charging, just prior to shock delivery. ${ }^{18}$ (Conceivably, some of the appropriate ICD therapies in the class IV patients of Desai et al. may have 
TABLE 1

Randomized Clinical Trials of Device Therapy in Patients with LV Systolic Dysfunction

\begin{tabular}{|c|c|c|c|c|c|c|c|c|}
\hline Trial & Device & $\begin{array}{c}\text { Type of } \\
\text { Prevention } \\
\text { Trial }\end{array}$ & $\begin{array}{l}\text { Primary } \\
\text { End Point }\end{array}$ & $\begin{array}{l}\text { Upper } \\
\text { Limit } \\
\text { LVEF }\end{array}$ & $\begin{array}{c}\text { QRS } \\
\text { Duration } \\
\text { Requirement (ms) }\end{array}$ & $\begin{array}{l}\text { NYHA } \\
\text { Class } \\
\text { Range }\end{array}$ & $\begin{array}{l}\text { Number of } \\
\text { Patients }\end{array}$ & $\begin{array}{c}\text { NYHA } \\
\text { Class IV } \\
\text { (No. [\%]) }\end{array}$ \\
\hline AVID (3) & ICD & $2^{\circ}$ & Mortality & 0.40 & None & I-III & 1,016 & $0(0)$ \\
\hline MADIT (4) & ICD & $1^{\circ}$ & Mortality & 0.35 & None & I-III & 196 & $0(0)$ \\
\hline CABG-Patch (5) & ICD & $1^{\circ}$ & Mortality & 0.35 & None & I-IV & 900 & $64(7)$ \\
\hline MUSTT (6) & ICD & $1^{\circ}$ & $\mathrm{CA} / \mathrm{AD}$ & 0.40 & None & I-III & 704 & $0(0)$ \\
\hline MADIT II (7) & ICD & $1^{\circ}$ & Mortality & 0.30 & None & I-IV & 1,232 & $9(0.1)$ \\
\hline DEFINITE (8) & ICD & $1^{\circ}$ & Mortality & 0.35 & None & I-III & 458 & $0(0)$ \\
\hline SCD-HeFT (9) & ICD & $1^{\circ}$ & Mortality & 0.35 & None & II-III & 2,521 & $0(0)$ \\
\hline MIRACLE (10) & CRT & $1^{\circ}$ & $\mathrm{HF}$ parameters & 0.35 & $>130$ & III-IV & 453 & $43(9)$ \\
\hline MUSTIC (11) & CRT & $1^{\circ}$ & HF parameters & 0.34 & $>150$ & III & 131 & $0(0)$ \\
\hline MIRACLE-ICD (12) & CRT-D & $1^{\circ}+2^{\circ}$ & $\mathrm{HF}$ parameters & 0.35 & $\geq 130$ & III-IV & 369 & $41(11)$ \\
\hline $\begin{array}{l}\text { Ventak CHF/ } \\
\text { Contak ICD (13) }\end{array}$ & CRT-D & $1^{\circ}+2^{\circ}$ & $\begin{array}{l}\text { HF parameters } \\
+ \text { Mortality }\end{array}$ & 0.35 & $\geq 120$ & II-IV & 490 & $29(6)$ \\
\hline COMPANION (14) & CRT/CRT-D & $1^{\circ}$ & Mortality + Hosp & 0.35 & $\geq 120$ & III-IV & 1,520 & $218(14)$ \\
\hline $\begin{array}{l}\text { CARE-HF (15) } \\
\text { Total }\end{array}$ & CRT & $1^{\circ}$ & Mortality + Hosp & 0.35 & $\geq 120$ & III-IV & $\begin{array}{r}813 \\
10,803\end{array}$ & $\begin{array}{c}50(6) \\
454(4.2)\end{array}$ \\
\hline
\end{tabular}

$\overline{\mathrm{AVID}}=$ Antiarrhythmics vs. Implantable Defibrillator; CA/AD = cardiac arrest/arrhythmic death; CABG = coronary artery bypass graft; CARE-HF $=$ cardiac resynchronization-heart failure; ICD = implantable cardioverter defibrillator; CHF = congestive heart failure; COMPANION = Comparison of Medical Therapy, Pacing and Defibrillation in Heart Failure; CRT = cardiac resynchronization therapy; CRT-D = cardiac resynchronization therapy with Defibrillator; DEFINITE = Defibrillators in Non-ischemic Cardiomyopathy Treatment Evaluation; Hosp = hospitalization; HF = heart failure; LV = left ventricular; LVEF = left ventricular ejection fraction; MADIT = Multicenter Automatic Defibrillator Implantation Trail; MIRACLE = Multicenter InSynch Randomized Clinical Evaluation; MUSTIC = Multisite Stimulation in Cardiomyopathy; MUSTT = Multicenter Unsustained Tachycardia Trial; NYHA = New York Heart Association; SCD-HeFT = Sudden Cardiac Death Heart Failure Trial.

reflected antitachycardia pacing for relatively slow, tolerated non-sustained or sustained VTs, but the authors do not provide data on programmed tiered therapy configurations, or types of appropriate therapies delivered and their associated stored electrograms.) The alternative postulation that many ICD therapy events in the class IV patients may have resulted from sustained VTs that would have (eventually) terminated spontaneously - based on observations from the DEFINITE trial, ${ }^{19}$ limited to non-ischemic cardiomyopathy patients of NYHA classes I-III-overlooks the fact that such protracted tachyarrhythmias in class IV patients, especially those with ischemic cardiomyopathy (the predominant pathology in the series of Desai et al.), are less likely to be tolerated than in class III patients and carry significant risk of degeneration to VF (i.e., SCD). Moreover, studies of patients receiving an ICD (mostly for secondary prevention), while they await cardiac transplantation, show the following: (a) a 6-month appropriate ICD shock rate of similar order of magnitude to the ICD therapy rate reported by the authors for their class IV patients ${ }^{20,21}$; (b) equivalence between appropriate ICD therapy and incidence of SCD, as evident from a comparison of survival curves for transplant-listed patients with versus without an $\mathrm{ICD}^{21}$; and, (c) absence of SCD events among transplant-listed ICD implantees versus non-implantees. ${ }^{21,22}$ Thus, the greater frequency of appropriate ICD therapy delivery in class IV versus class III patients, as reported by Desai et al., would seem to largely represent a true difference in the incidence of potentially life-threatening ventricular tachyarrhythmic events, at least over the 6-month follow-up period.

\section{Factors Influencing Incidence of Appropriate ICD Therapy Delivery in CRT-D Implantees}

In trying to understand the finding of the authors, it is important to consider a number of factors that are operative in CRT-D treated patients.

\section{Prolonged QRS Duration as Inclusion Criterion for CRT Therapy (with or without Defibrillator Capability)}

As demonstrated in the large CHF-STAT amiodarone trial database, ${ }^{23,24}$ taking a population of patients with LV dysfunction (LVEF $\leq 0.40$, predominantly NYHA classes II and III, 4\% class IV) and then subselecting those with QRS duration $\geq 120 \mathrm{~ms}$ (i.e., 290 of $669=43 \%$ of the study cohort) increases the crude SCD rate to nearly $25 \%$ from $21 \%$ in the parent population; one can further calculate that the corresponding crude rate of pump failure deaths increases to $15 \%$ from $11 \%$ and that, consequently, crude total cardiac mortality rises to $40 \%$ from $32 \%$, respectively (working backward from the total mortality data for the restricted QRS duration population $^{24}$ and assuming an unchanged overall $9 \%$ rate of non-cardiac or unclassified death ${ }^{23}$ ). How the magnitude of changes in mortality rates consequent to the requirement of prolonged QRS duration for CRT-D eligibility would play out in NYHA class IV versus class III patients-with potential differential quantitative impact on rates of appropriate ICD therapy_remains to be determined.

\section{Effect of CRT}

Whereas screening for CRT or CRT-D implantation eligibility according to QRS duration selects a subset of advanced HF patients with increased SCD and pump failure mortality, once the device is implanted, its CRT function then acts in the opposite direction to decrease these mortality rates. ${ }^{14,15}$ Whether or not such opposing effects on cardiac mortality completely cancel out and whether the net effect may differ by pre-existing functional class is not yet known. It has been reported by Lecoq et al., ${ }^{25}$ however, that at 6 months, a similar proportion $(\sim 80 \%)$ of NYHA class III and class IV patients were clinical responders to CRT; and another study ${ }^{26}$ found that early improvements in HF parameters were maintained during CRT for at least 3 years. Two recent observational 
studies $^{27,28}$ offer concordant evidence that CRT therapy can also decrease the incidence of appropriate ICD therapy. If confirmed by additional studies, it would be of interest to investigate whether such a favorable response may be influenced by pre-CRT functional class. For example, maybe the differential incidence of appropriate ICD therapy reported by Desai et al. ${ }^{16}$ results from a more marked reduction in tachyarrhythmic event rates in functional class III versus class IV patients.

\section{Study Limitations}

It is important to emphasize that the Ventak CHF/Contak CD patient population studied by the authors was a tachyarrhythmia-event-prone group by virtue of the fact that three-fourths of them had spontaneous sustained ventricular tachyarrhythmias and the other one-fourth had inducible sustained ventricular tachyarrhythmias. Whether the observed disparate incidence rates of appropriate ICD therapy according to functional class represents a more generalizable phenomenon, that would also occur when CRT-D devices are implanted in advanced HF patients without spontaneous or inducible sustained ventricular tachyarrhythmias (as in COMPANION $^{14}$ ), remains to be determined.

The issue of the potential confounding effect of absolute QRS duration (and, ideally, more informative measures of left ventricular dyssynchrony ${ }^{29}$ ) also must be considered. For CRT or CRT-D therapy, both COMPANION ${ }^{14}$ and CARE$\mathrm{HF}^{15}$ reported a trend toward greater benefit, as per the composite endpoint of all-cause mortality or hospitalization (and similarly for all-cause mortality with CRT-D alone in COMPANION), in those patients who had more prolonged QRS durations. In the study of Desai et al., ${ }^{16}$ a QRS duration of $>160 \mathrm{~ms}$ was associated with a hazard ratio of 1.29 for appropriate ICD therapy, but at a $\mathrm{P}$ value of 0.13 (possibly reflecting reduced power, and just over the usual cutoff $[\leq$ $0.10]$ for incorporation into multivariable analyses). Since QRS duration was not included in the multivariable analysis, we do not know the extent to which the impact of NYHA class IV as a predictor of appropriate ICD therapy might have been diluted (note modest $\mathrm{P}$ value of $<0.02$ ). To confirm and strengthen the authors' observations, therefore, future studies are needed that will incorporate into their design a larger number of class IV patients; measures of additional outcome predictors in HF; detailed analyses of appropriate ICD therapy events; echocardiographic measures of left ventricular dyssynchrony; and a longer follow-up period (at least 1-2 years).

\section{Implications}

Assuming the findings of Desai et al. ${ }^{16}$ are confirmed, what implications would this have for managing advanced HF patients? It is recognized that NYHA functional class labels in these patients may vary over time, particularly when considering degrees of class III (i.e., IIIa and IIIb) and episodic decompensations (transient "class IV"). If the simple "class IV"-versus "class III"-label truly implies a greater incidence of appropriate ICD therapy in CRT-D recipients, the pertinent clinical question raised is whether this translates into a greater number of days of life saved. In COMPANION,${ }^{14}$ there was no clear difference in the magnitude of CRT-D-associated reduction in all-cause mortality for pa- tients labeled as class IV versus class III; corresponding data from CARE-HF (limited to CRT alone) have not been published. Although COMPANION documented a favorable cost-effectiveness ratio for CRT and CRT-D, ${ }^{30}$ only $14 \%$ of that trial's enrollees had class IV symptoms. The potential clinical relevance of the findings of Desai et al. will only emerge in the context of a greater understanding of the impact of CRT and CRT-D on survival, and the broader issue of cost effectiveness of such therapies, in HF studies with more substantial representation of class IV patients.

\section{References}

1. DEFIBRILAT Study Group: Actuarial risk of sudden death while awaiting cardiac transplantation in patients with atherosclerotic heart disease. Am J Cardiol 1991;68:545-546.

2. MERIT-HF Study Group: Effect of Metoprolol CR/XL in chronic heart failure: Metoprolol CR/XL randomized intervention trial in congestive heart failure (MERIT-HF). Lancet 1999;353:2001-2007.

3. The Antiarrhythmics versus Implantable Defibrillators (AVID) Investigators: A comparison of antiarrhythmic-drug therapy with implantable defibrillators in patients resuscitated from near-fatal ventricular arrhythmias. N Engl J Med 1997;337:1576-1583.

4. Moss AJ, Hall J, Cannom DS, Daubert JP, Higgins SL, Klein H, Levine JH, Saksena S, Waldo AL, Wilbe r D, Brown MW, Heo M, for the Multicenter Automatic Defibrillator Implantation Trial Investigators: Improved survival with an implanted defibrillator in patients with coronary disease at high risk for ventricular arrhythmia. N Engl J Med 1996;326:1933-1940

5. Curtis AB, Cannom DS, Bigger T, DiMarco JP, Estes NAM, Steinman RC, Parides MK: Baseline characteristics of patients in the coronary artery bypass graft (CABG) patch trial. Am Heart J 1997;133:787-798.

6. Buxton AE, Lee KL, Fisher JD, Josephson ME, Prystowsky EN, Hafley G, for the Multicenter Unsustained Tachycardia Trail Investigators: A randomized study of the prevention of sudden death in patients with coronary artery disease. N Engl J Med 1999;341:1882-1890.

7. Moss AJ, Zareba W, Hall J, Klein H, Wilber DJ, Cannom DS, Daubert JP, Higgins SL, Brown MW, Andrews ML, for the Multicenter Automatic Defibrillator Implantation Trial II Investigators: Prophylactic implantation of a defibrillator in patients with myocardial infarction and reduced ejection fraction. N Engl J Med 2002;346:877-883.

8. Kadish A, Dyer A, Daubert JP, Quigg R, Estes M, Anderson KP, Calkins H, Hoch D, Goldberger J, Shalaby A, Sanders WE, Schaechter A, Levine JH, for the Defibrillators in Non-Ischemic Cardiomyopathy Treatment Evaluation (DEFINITE) Investigators: Prophylactic defibrillator implantation in patients with non-ischemic dilated cardiomyopathy. N Engl J Med 2004;350:2151-2158.

9. Bardy GH, Lee KL, Mark DB, Poole JE, Packer DL, Boineau R, Domanski M, Troutman C, Anderson J, Johnson G, McNulty SE, ClappChanning N, Davidson-Ray LK, Fraulo ES, Fishbein DP, Luceri RM, Ip HJ, for the Sudden Cardiac Death in Heart Failure Trial (SCD-HeFT) Investigators: Amiodarone or an implantable cardioverter-defibrillator for congestive heart failure. N Engl J Med 2005;352:225-237.

10. Abraham WT, Fisher WG, Smith AL, Delurgio DB, Leon AR, Loh E, Kocovic DZ, Packer M, Clavell AL, Hayes DL, Ellestad M, Messenger J, for the MIRACLE Study Group: Cardiac resynchronization in chronic heart failure. N Engl J Med 2002;346:1845-1853.

11. Linde C, Leclercq C, Rex S, Garrigue S, Lavergne T, Cazeau S, McKenna W, Fitzgerald M, Deharo JC, Alonso C, Walker S, Braunschweig F, Bailleul C, Daubert JC, on behalf of the MUltisite STimulation In Cardiomyopathy (MUSTIC) Study Group: Long-term benefits of biventricular pacing in congestive heart failure: Results from the MUltisite STimulation In Cardiomyopathy (MUSTIC) Study. J Am Coll Cardiol 2002;40:111-118.

12. Young JB, Abraham WT, Smith AL, Leon AR, Lieberman R, Wilkoff B, Canby RC, Schroeder JS, Liem LB, Hall S, Wheelan K, for the Multicenter InSync ICD Randomized Clinical Evaluation (MIRACLE ICD) Trial Investigators: Combined cardiac resynchronization and implantable cardioversion defibrillation in advanced chronic heart failure: The MIRACLE ICD trial. JAMA 2003;289:2685-2694.

13. Higgins SL, Hummel JD, Niazi IK, Giudici MC, Worley SJ, Saxon LA, Boehmer JP, Higginbotham MB, De Marco T, Foster E, Yong PG: Cardiac resynchronization therapy for the treatment of heart failure 
in patients with intraventricular tachyarrhythmias. J Am Coll Cardiol 2003;42:1454-1459.

14. Bristow MR, Saxon LA, Boehmer J, Krueger S, Kass DA, De Marco T, Carson P, DiCarlo L, DeMets D, White BG, DeVries DW, Feldman AM, for the Comparison of Medical Therapy, Pacing, and Defibrillation in Heart Failure (COMPANION) Investigators: Cardiacresynchronization therapy with or without an implantable defibrillator in advanced chronic heart failure. N Engl J Med 2004;350:21402150 .

15. Cleland JGF, Daubert JC, Erdmann E, Freemantle N, Gras D, Kappenberger L, Tavazzi L, for the Cardiac Resynchronization-Heart Failure (CARE-HF) Study Investigators: The effect of cardiac resynchronization on morbidity in heart failure. N Engl J Med 2005;352:15391549.

16. Desai AD, Burke MC, Hong TE, Kim S, Salem Y, Yong PG, Knight BP: Predictors of appropriate defibrillator therapy among patients with an implantable defibrillator that delivers cardiac resynchronization therapy. J Cardiovasc Electrophysiol 2006;17:486-490.

17. Uretsky BF, Sheahan RG: Primary prevention of sudden cardiac death in heart failure: Will the solution be shocking? J Am Coll Cardiol 1997;30:1589-1597.

18. Wathen MS, Degroot PJ, Sweeney MO, Stark AJ, Otterness MF, Adkisson WO, Canby RC, Khalighi K, Machado C, Rubenstein DS, Volosin KJ, for the PainFREE Rx II Investigators: Prospective randomized multicenter trial of empirical antitachycardia pacing versus shocks for spontaneous implantable cardioverter-defibrillators: Pacing fast ventricular tachycardia reduces shock therapies (PainFREE Rx II) trial results. Circulation 2004;110:2591-2596.

19. Ellenbogen KA, Levine JH, Berger RD, Daubert JP, Winters SL, Greenstein E, Shalaby A, Schaechter A, Subacius H, Kadish A, for the Defibrillators in Non-Ischemic Cardiomyopathy Treatment Evaluation (DEFINITE) Investigators: Are implantable cardioverter defibrillator shocks a surrogate for sudden cardiac death in patients with nonischemic cardiomyopathy? Circulation 2006;113:776-782.

20. Saxon LA, Wiener I, DeLurgio DB, Natterson PD, Laks H, Drinkwater DC, Stevenson WG: Implantable defibrillators for high-risk patients with heart failure who are awaiting cardiac transplantation. Am Heart J 1995;130:501-506.

21. Saba S, Atiga WL, Barrington W, Ganz LI, Kormos RL, MacGowan GA, Mathier MA, McNamara DM, Obioha-Ngwu O, Murali S: Selected patients listed for cardiac transplantation may benefit from defibrilla- tor implantation regardless of an established indication. J Heart Lung Transplant 2003;22:411-418.

22. Sandner SE, Wieselthaler G, Zuckermann A, Taghavi S, Schmidinger H, Pacher R, Ploner M, Laufer G, Wolner E, Grimm M: Survival benefit of the implantable cardioverter-defibrillator in patients on the waiting list for cardiac transplantation. Circulation 2001;104(Suppl I):I171-I176.

23. Singh SN, Fletcher RD, Fisher SG, Singh BN, Lewis HD, Deedwania PC, Massie BM, Colling C, Lazzeri D, for the Survival Trial of Antiarrhythmic Therapy in Congestive Heart Failure: Amiodarone in patients with congestive heart failure and asymptomatic ventricular arrhythmia. N Engl J Med 1995;333:77-82.

24. Iuliano S, Fisher SG, Karasik PE, Fletcher RD, Singh SN, for the Department of Veterans Affairs Survival Trial of Antiarrhythmic Therapy in Congestive Heart Failure: QRS duration and mortality in patients with congestive heart failure. Am Heart J 2002;143:1085-1091.

25. Lecoq G, Leclercq C, Leray E, Crocq C, Alonso C, de Place C, Mabo $\mathrm{P}$, Daubert C: Clinical and electrocardiographic predictors of a positive response to cardiac resynchronization therapy in advanced heart failure. Eur Heart J 2005;26:1094-1100.

26. Molhoek SG, Bax JJ, Bleeker GB, Holman ER, Van Erven L, Bootsma M, Boersma E, Steendijk P, Van Der Wall EE, Schalij MJ: Long-term follow-up of cardiac resynchronization therapy in patients with endstage heart failure. J Cardiovasc Electrophysiol 2005;16:701-707.

27. Higgins SL, Yong P, Scheck D, McDaniel M, Bollinger F, Vadecha M, Desai S, Meyer DB, for the Ventak CHF Investigators: Biventricular pacing diminishes the need for implantable cardioverter defibrillator therapy. J Am Coll Cardiol 2000;36:824-827.

28. Arya A, Haghjoo M, Dehghani MR, Alasti M, Alizadeh H, Kazemi B, Sadr-Ameli MA: Effect of cardiac resynchronization therapy on the incidence of ventricular arrhythmias in patients with an implantable cardioverter-defibrillator. Heart Rhythm 2005;2:1094-1098.

29. Bleeker GB, Schalij MJ, Molhoek SG, Verwey H, Holman ER, Boersma E, Steendijk P, Vander Wall EE, Bax JJ: Relationship between QRS duration and left ventricular dyssynchrony in patients with end-stage heart failure. J Cardiovasc Electrophysiol 2004;15:544-549.

30. Feldman AM, de Lissovoy G, Bristow MR, Saxon LA, De Marco T, Kass DA, Boehmer J, Singh S, Whellan DJ, Carson P, Boscoe A, Baker TM, Gunderman MR: Cost effectiveness of cardiac resynchronization therapy in the comparison of medical therapy, pacing and defibrillation in heart failure (COMPANION) trial. J Am Coll Cardiol 2005;46:23112321. 